\title{
REVIEWS
}

Marta MrużyńsKa $^{\text {B, D }}$, Urszula Kanaffa-KilijaŃskA ${ }^{\text {E, F }}$

\section{Irrigants Used in Endodontic Treatment \\ - Review of the Literature}

\section{Środki płuczące stosowane w leczeniu endodontycznym - przegląd piśmiennictwa}

Department of Conservative and Pediatric Dentistry, Wroclaw Medical University, Wrocław, Poland

A - research concept and design; $\mathbf{B}$ - collection and/or assembly of data; $\mathbf{C}$ - data analysis and interpretation;

$\mathbf{D}$ - writing the article; $\mathbf{E}$ - critical revision of the article; $\mathbf{F}$ - final approval of article

\begin{abstract}
Endodontic treatment can be successful if we use the appropriate techniques to prepare the canals in combination with the correct application of chemical agents and tight sealing of the root canal system. After the mechanical preparation of the canal, a lot of bacteria remains in the numerous branches, and the presence of bacteria in the canal has a negative influence on the final treatment result. The use of a rinsing agent supports the removal of intracanal micro-organisms and obtaining effective disinfection, which increases the probability of success of endodontic treatment.

This study presents a review of the literature concerning the rinsing means which are used most often during root canal treatment. The authors describe the antibacterial properties of sodium hypochlorite and chlorhexidine, novel irrigants such as alexidine and octenidine, peroxide's effect, the effect of chelation agents like disodium versenate and citric acid, and also ethyl and isopropyl alcohol. Unfortunately, there is not a canal rinsing liquid which could fulfill all the requirements. Therefore, it is extremely important to know all the negative and positive points of particular preparations and the scope of their activity in order to use such an agent in the correct way, depending on the clinical situation (Dent. Med. Probl. 2015, 52, 4, 491-498).
\end{abstract}

Key words: EDTA, chlorhexidine, root canal rinsing, sodium hypochlorite, endodontics.

Słowa kluczowe: EDTA, chlorheksydyna, płukanie kanałów korzeniowych, podchloryn sodu, endodoncja.

The key to successful endodontic treatment is both the appropriate chemical agents and a correctly, tightly-sealed root canal system.

The aim of this thesis is to present a review of the literature concerning the rinsing means which are used most often during root canal treatment.

It is possible to achieve a nearly complete shape of the canals using manual and machine preparation techniques [1]. On account of the complicated structure of the root canal system, even mechanical preparation is not enough to achieve aseptic canals. According to tests by Peters et al. [2], regardless of the chosen instrumentation technique following the mechanical preparation of canals, over $35 \%$ of their surface remains untouched by dental instruments.
There is a considerable amount of bacteria in numerous branches and ducts, and their presence in the canal before filing might have a negative impact on the final treatment result. According to Sjogren et al. [3] in the case when no bacteria was found before filing in the canals, the success was $94 \%$, while in the teeth where bacteria was isolated, it was $68 \%$.

The use of rinsing agents supports the removal of intracanal micro-organisms and obtaining effective disinfection and it increases the probability of successful endodontic treatment.

The perfect rinsing agent should contain the following properties:

- a germicidal effect, at least a bacteriostatic one, 
- the ability to dissolve the organic and inorganic content of the canal, even in places which are inaccessible for instruments,

- removing the smear layer from walls of the canal,

- removing the dentine chips and other debris from all sections of the root canal,

- help in preparing narrow and curved canals,

- reducing the emergence of instrument fracture in the canal [4].

Unfortunately, there is no canal rinsing liquid which could fulfill all these requirements. Therefore, it is extremely important to know all the negative and positive points of particular preparations and the scope of their activity. This would allow us to use each agent in the correct way, depending on the clinical situation. The most used ones are: sodium hypochlorite (0.5-5.25\%), chlorhexidine (2\%), alexidine, octenidine, 3\% peroxide, EDTA, citric acid, MTAD, ethyl and isopropyl alcohol.

\section{Sodium Hypochlorite}

Sodium hypochlorite is the basic rinsing agent which is used during endodontic treatment. It is a hypochlorous acid, sodium salt with the chemical formula NaOCL. The concentrations of hypochlorite which are used in root canal treatment are between $0.5 \%$ and $5.25 \%$. Hypochlorite has many characteristics which are expected of fluids to rinse the root system. It has a broad spectrum of activity; it destroys the vegetative forms of bacteria, fungi and their spores and also viruses. It shows strong antibacterial properties even shortly after application [5]. It is effective against more resistant bacteria such as Enterococci spp., Actinomyces spp. and also Candida albicans [5-7]. In most of the in vivo studies there was no significant difference in the antibacterial properties when comparing the effects of concentrations of hypochlorite $0.5 ; 1 ; 2.5 ; 5 \%$, in relation to mixed anaerobic flora and Enterococcus faecalis. The problem is in endodontic cases of secondary infections, in which $E$. faecalis is the main representative of the bacterial flora [8]. These bacteria are characterized by significant resistance to sodium hypochlorite; therefore it is strongly recommended that during endodontic re-treatment, chlorhexidine, an agent which is significantly more effective in eliminating $E$. faecalis, be used. An important advantage of sodium hypochlorite is its ability to dissolve organic tissue without damaging the hard tooth tissue at lower concentrations [4]. Some practitioners recommend using 5.25\% hypochlorite because the higher the concentration of the solution the greater the ability to dissolve organic tissues. A solution of $5.25 \%$ was more effective in dissolving the vital and necrotic tissue in comparison to solutions of $0.5 \%, 1 \%$ and $2.5 \%$ [9]. There were no significant differences between the solutions of $2.5 \%$ and $5 \% \mathrm{NaOCl}$. Differences were visible between the concentrations of $2.5 \%$ or $5 \%$ and the $0.5 \%$ solution. A hypochlorite solution at a concentration of $0.5 \%$ did not show any tissue dissolution effects [8]. With the increase in the concentration of hypochlorite, its toxicity increases significantly, while the bactericidal effect is only slightly stronger [10]. Therefore, solutions of $2 \%$, which have less toxicity with a simultaneous sufficient effect of dissolving the organic tissue, are recommended for general use [4]. 5.25\% hypochlorite can be used for the irrigation of canals with internal resorption, because of the greater effectiveness of this solution in the dissolution of granulation tissue, which can not be removed mechanically from the postresorptive craters [11]. The disadvantage of sodium hypochlorite is its lack of ability to remove the smear layer; this agent does not work on dentin inorganic substance. Therefore, $\mathrm{NaOCl}$ should be used alternately with chelating compounds (EDTA, citric acid), which allows for the liquidation of the smear layer from the walls of the prepared canal [12]. Another disadvantage of hypochlorite is its unpleasant odor and taste, as well as the possibility of causing allergic reactions [13]. It is important that you can raise the efficiency of dissolving pulp with $\mathrm{NaOCl}$ by increasing the temperature of the washing fluid or by using ultrasonic activation instead of the conventional syringe and needle [14]. Research has shown that $1 \%$ of $\mathrm{NaOCl}$ at a temperature of $45^{\circ} \mathrm{C}$ is just as effective in dissolving pulp as $5.25 \%$ solution at $20^{\circ} \mathrm{C}$ [15].

\section{Chlorhexidine - CHX}

This is one of the most used antiseptics in dentistry. It works bacteriostatically, germicidally against Gram-positive and Gram-negative bacteria and virucidally. It also shows great effectiveness in eliminating fungal infections [16]. Chlorhexidine has a strong positive charge which allows it to connect through electrostatic forces with the negatively charged bacterial cytoplasmic membrane. As a result of this connection, the cell membrane permeability of micro-organisms increases, the osmotic equilibrium is disturbed and a leakage of intracellular material occurs, resulting in the death of bacterial cells [8]. The advantage of chlorhexidine is substantivity, which means that it exhibits adhesion to the hydroxyapatite of the enamel and dentin; it is also released gradually, thereby extending the duration of its antiseptic effect [17]. Most authors agree that chlorhexidine should be 
used during the preparation of canals as a rinsing agent at a concentration of $2 \%$ [9]. Chlorhexidine is characterized by its biocompatibility. It is also safer for periapical tissues in comparison to $\mathrm{NaOCl}$. However, due to the major limitation of chlorhexidine, i.e. its inability to dissolve some organic tissues such as pulp remains, it cannot replace hypochlorite as a rinsing agent of choice [18]. Contact of chlorhexidine with dentin, inflammatory exudate or the remains of bacteria results in its fast neutralization because it is sensitive to the presence of organic tissue [8]. Another disadvantage is that it does not remove the smear layer. On the other hand, chlorhexidine's substantial advantage is its high effectiveness in eliminating Enterococcus faecalis and fungal infections. Onca et al. [19] conducted a study which compared the toxicity and antimicrobial activity in relation to E. faecalis $5.25 \%$ sodium hypochlorite and $2 \%$ and $0.2 \%$ chlorhexidine solution used for rinsing the root canals. They found that both solutions of chlorhexidine are effective and, in addition, the hypochlorite toxicity was much higher. Other studies showed that only in $5.25 \% \mathrm{NaOCl}$ was its bactericidal effect comparable to that of $1 \%$ and $2 \%$ chlorhexidine [9]. It is interesting that chlorhexidine used in combination with $3 \%$ hydrogen peroxide is more effective in combating E. faecalis bacteria than the independent use of both of these two fluids [20]. It is, however, inadvisable to use chlorhexidine as a rinsing agent immediately after $\mathrm{NaOCI}$, as there is a chemical reaction which takes place between them, leading to the formation of a precipitate containing para-chloroaniline (PCA) [21-23]. PCA is highly toxic and is potentially carcinogenic, which has been observed in animal tests [24]. Therefore, it is recommended to use an additional rinsing agent between $\mathrm{NaOCl}$ and $\mathrm{CHX}$, e.g. alcohol or EDTA, which prevents the formation of the dental deposit. There are some benefits of using chlorhexidine at the end of rinsing. Chlorhexidine has a beneficial effect on the tightness of epoxy sealants and its bacteriostatic activity remains effective even after filling the canal [25].

\section{Alexidine - ALX}

Another bisbiguanide is alexidine (ALX), which has been previously used as a conventional mouthwash and contact lens solution [26]. Alexidine is similar to chlorhexidine but proven to have a faster bactericidal action and bacterial permeabilization because of the presence of two hydrophobic ethylhexyl groups in its structure [27]. Alexidine has higher affinity for bacterial lipopolysaccharide and LTA than chlorhexidine. Con- sequently, the new irrigant has greater antimicrobial action at a lower concentration [28]. 1\% ALX can be as effective against Enterococcus faecalis infections as $2 \%$ CHX [27]. Both agents observed eradicated the same amount of bacteria from dentin [29]. Furthermore, in a comparison of both agents, ALX shows lower toxicity when applied topically to corner tissue in vivo [26]. Recent studies have also reported that the interaction of ALX and $\mathrm{NaOCl}$ did not form an insoluble precipitate or PSA, as with CHX, and the color of the reacted solution changed transparent with decreasing ALX concentration. The present results indicate that a combination of ALX and $\mathrm{NaOCl}$ can be safely used as a canal root irrigant during canal instrumentation [30]. The authors have also reported that ALX has been tested and proved to be the first bisbiguanide compound used for anticancer specificity [29].

\section{Octenidine - OCT}

This is one of the latest antiseptics proposed as an alternative to chlorhexidine. Octenidine hydrochloride (OCT) is a bipyridine derivative, that is, [N, N'-(1,10-decanediyldi-1[4H]-piridinyl-4-ylidyne)bis(1-octanamine)dihydrochloride]. OCT has been shown to be a mucous membrane antiseptic, and is also used in severe burns and for promoting wound healing [31]. Its use as an endodontic irrigant was suggested because of its antibacterial effects and lower cytotoxicity. It possesses broad-spectrum antimicrobial effects against both Gram-positive and Gram-negative bacteria and fungi and several viral species and the model of effects is bactericidal/fungicidal by interfering with cell walls and membranes [32]. It has been demonstrated that octenidine hydrochloride appears to be more effective than chlorhexidine (CHX) as a means of prolonged bacterial anti-adhesive activity [33]. Experimental studies have shown that both CHX- and octenidine-based intracanal treatments were effective in decreasing the viability of E. faecalis, and OCT showed the most favorable results, thus showing possible potential as an endodontic treatment [34]. Mixing OCT with calcium hydroxide significantly increased the antibacterial effect of Octenisept ${ }^{\circledR}$, but did not alter its antifungal activity, unlike in regards to the use of CHX alone, which yielded a higher antibacterial and antifungal efficiency compared to that of its combined version with $\mathrm{Ca}(\mathrm{OH})_{2}$ [35]. Tirali et al. [36] made a study to compare the antimicrobial efficiency of various endodontic irrigants including $\mathrm{NaOCl}, \mathrm{CHX}$ and OCT in different concentrations on selected root canal microorganisms 
like E. faecalis, C. albicans and a mixture of them both. The results of this study indicated that various concentrations of octenidine dihydrochloride were as effective as a $5.25 \%$ solution on the tested microorganisms, and the inhibition zones observed with $\mathrm{CHX} 2 \%$ and $1 \%$ groups were significantly less than $\mathrm{NaOCl}$ and octenidine. In other studies, octenidine proved to be more effective against $E$. faecalis than $5 \%$ sodium hypochlorite, and $100 \%$ and $50 \%$ Octenisept eliminated all the tested microorganisms in only 15 seconds [31]. The in vitro antimicrobial effect of the tested irrigants were ranked from strongest to weakest as follows: $100 \%$ Octenisept, 50\% Octenisept, 5.25\% $\mathrm{NaOCl}$ and $2.5 \% \mathrm{NaOCl}$. The results were similar to a study by Anuradha et al. [37], in which octenidine was found to be more effective than a $5.25 \% \mathrm{NaOCl}$ solution against $E$. faecalis as an antimicrobial endodontic irrigant. To our knowledge, there is no study in the literature about allergic reactions of Octenisept on gingiva and oral tissues, and the allergenic potential is classified as low, based on the data obtained from a previous animal study [38].

\section{Peroxide $-\mathrm{H}_{2} \mathrm{O}_{2}$}

A solution of $3 \%$ peroxide is commonly used in endodontics. Hydrogen peroxide has antibacterial properties - bleaching and dissolving the organic tissue. As a result of the decomposition of $\mathrm{H}_{2} \mathrm{O}_{2}$ under the influence of tissue catalase, $\mathrm{O}_{2}$ is emitted and it causes the formation of foam, supporting the mechanical cleaning of the canal from the remaining pulp and dentin chips [11]. The dissolution effect of organic tissues after rinsing the canal with hydrogen peroxide is much smaller than with hypochlorite. On the basis of studies, it was found that there was no difference in the removal efficiency of contamination from the canal between sodium hypochlorite with hydrogen peroxide and hypochlorite alone [39]. Additionally, peroxide reduces sodium hypochlorite's ability to dissolve organic tissue and its antibacterial properties while the oxygen, which is isolated in the reaction, may cause pain in the periapical tissues. Therefore, in order to eliminate the remains of the oxygen from the canals, the last rinse should be done with a preparation other than peroxide [4]. The undoubted advantage of $\mathrm{H}_{2} \mathrm{O}_{2}$, in comparison to hypochlorite, is less toxicity to periapical tissues and that is why for many years, the use of $3 \%$ peroxide to rinse the canals with unshaped foramina, with perforations or with excessively enlarged physiological foramina was recommended. Unfortunately, the antibacterial effect of perox- ide is insufficient, and pushing it to the periapical tissues may cause edema. Another rinse agent which can be pushed beyond the apical foramina and does not damage the periodontal tissues and can be used in the treatment of teeth with unfinished root growth is chlorhexidine. However, due to the fact that it does not ensure the removal of the smear layer from the walls of the canals, it is necessary to use a chelating agent [40].

\section{EDTA}

Another group of agents used for the preparation of canals are chelation compounds, which include EDTA and citric acid. Sodium versenate, commonly known as EDTA, is the most popular chelation agent. EDTA is most commonly used in endodontics at a concentration of $17 \%$ and a $\mathrm{PH}$ of 7. This agent has the ability to "soften" the dentine. This effect of EDTA is derived from its ability to capture calcium and magnesium ions from the dentin and their conversion to sodium ions, resulting in the formation of water-soluble compounds [41]. A certain volume of rinse solution EDTA can bind a limited amount of calcium ions, so to maintain a fluid chelating effect, EDTA should changed frequently in the canal. The softened dentine is easier to prepare with mechanical instruments. Therefore, the use of EDTA is particularly recommended for narrow and strong obliterated canals, but this should be done with care because the improper use of chelating agents and excessive exposure to EDTA contribute to an increased risk of the perforation or the distortion of the canal [8]. EDTA is well tolerated by the periapical tissues and has little antibacterial effect [4]. In vitro tests have shown that it also has antifungal properties and it is effective in killing E. faecalis [42]. EDTA is able to remove the inorganic part of the smear layer from the walls of the canal. In order to remove the smear layer, EDTA should be used alternately with $\mathrm{NaOCl}$, which effectively removes the organic portion. The smear layer covers the canal's walls after its final widening. It consists of fragments of prepared root dentin, remains of living and necrotic pulp, bacteria and rinsing fluid residues. The smear layer, on the one hand, protects the dentinal tubules against the penetration of microorganisms, but, on the other hand, it reduces the diffusion of fluids and drugs used in endodontic treatment, which makes disinfection difficult [43]. In addition, leaving a smear layer has an adverse effect on the tightness of root canal fillings. Therefore, in the opinion of most authors, the effective removal of the smear layer is a prerequisite for successful endodontic treat- 
ment $[44,45]$. By using $17 \%$ EDTA after finishing the instrumentation, we get the effective removal of the smear layer [46]. Using a $17 \%$ solution for 1 minute in combination with ultrasound activation can remove the smear layer from the periapical canal area [47]. Note, however, that after using EDTA, sodium hypochlorite should be used in order to neutralize the acidity of EDTA [39]. Grawehr et al. [48] have examined what impact EDTA has on sodium hypochlorite. They found that sodium versenate greatly limits the ability of hypochlorite to dissolve organic tissue and reduces the antimicrobial properties of hypochlorite. There are formulations containing EDTA in the shape of a gel, e.g. R-Prep Endogel ${ }^{\circledR}$ and Glyde ${ }^{\circledR}$. Most of the available lubricants have some antimicrobial properties, which help to disinfect root canals [49]. They facilitate work in narrow, curved canals and should be applied when such canals are being prepared mechanically. The presence of glycerol in its composition provides the necessary lubrication for tools, thus reducing the risk of fracture or wedging in the canal. Additionally, they capture calcium ions from the dentine to facilitate the expansion of the tooth cavity. These formulations should not be used during the preparation of patent and not obliterated root canals of teeth. These preparations have a significant influence on the properties of sodium hypochlorite, leading to its deactivation. The content of even small amounts of these preparations in a $1 \%$ solution of $\mathrm{NaOCl}$, eliminates all negative $\mathrm{OCl}$ ions [42]. The lubricants must be introduced into the canals before using each new file size, and after the removal of the tool, rinse the canal with sodium hypochlorite. If preparations containing urea peroxide were used, for example Rc-Prep, particularly abundant rinsing should be carried out after the completion of the preparation of the canal, until there are escaping bubbles from it into the air [50]. This prevents the symptoms of inflammation from the periapical tissues, due to the secretion of oxygen molecules by the remains of carbamide peroxide left in the canal.

\section{Citric Acid}

Citric acid (CA) may be an alternative rinsing agent to sodium. If it is used during endodontic treatment alternately with sodium hypochlorite, it effectively removes the smear layer $[5,51]$. It is recommended to use citric acid at concentrations of $40-50 \%$. Citric acid has a chelating effect similar to EDTA; it softens canal dentin and affects the properties of sodium hypochlorite. Therefore, after using $\mathrm{CA}$, a large amount of $\mathrm{NaOCl}$ should be added to the final rinse. Citric acid has an antibacterial effect on numerous anaerobic bacterial strains isolated from infected root canals. However, due to its insufficient antibacterial effect, it cannot be used as a single irrigant. According to many authors, you can achieve the same effect in removing impurities from the canal during rinsing using 40\% citric acid and sodium hypochlorite as $15-17 \%$ EDTA and $\mathrm{NaOCl} 2.5-5.25 \%$ [4]. Pawlicka, on the basis of her own and as well as other authors' research, concluded that $40 \%$ citric acid, which is particularly activated with ultrasound in combination with $5.25 \% \mathrm{NaOCl}$, effectively cleanses the wall of the dentin canal with contaminants remaining after mechanical preparation of the canal. It is worth noting that using citric acid gives the same effect of purity of the canal walls in less time than the EDTA currently used for this purpose [52].

\section{MTAD}

MTAD (Mixture of Tetracyclin, Acid and Detergent) is a mixture of isomers of tetracycline (doxycycline), 4.5\% citric acid and Tween 80 [53]. An additive of the antibiotic doxycycline in this case may have a bactericidal effect in higher concentrations [54]. The citric acid improves the ability of chelating agents while the detergent additive reduces the surface tension to allow deeper penetration of the dentin by the doxycycline. The most important advantage of MTAD is the antibacterial effect. MTAD used interchangeably with $2.5 \%$ $\mathrm{NaOCl}$ has a very high efficacy against $E$. faecalis [55]. In addition, MTAD effectively removes the smear layer and it simultaneously softens the dentin to weaker than EDTA.

\section{Alcohol}

Ethyl alcohol is often used as a last rinse agent before the final filling of canals. It reduces the surface tension of liquids and sealants and, in addition, by evaporating from the tubules, it dries the dentin surface, which allows for better penetration of the sealant. The in vitro studies of Stevens et al. [56] showed that a final rinse of 95\% ethanol significantly improved penetration of the sealant and decreased leakage. Shafer [20] recommends applying 95\% ethyl alcohol as the last rinse agent at a volume of $3 \mathrm{ml}$ per canal to enable the sealant to penetrate better and consequently ensure a tight seal of the canal. Wilcox and Wieman [57] found that, when they were using 95\% alcohol as the last rinse agent, they obtained better cover of 
the canal walls with a sealer in comparison to canals dried with paper filters, but these differences were not statistically significant. Additionally, they pointed out that rinsing with alcohol can prevent precipitation of crystals of sodium hypochlorite, if we use it at the end of the flushing protocol.

\section{Izopropyl alcohol}

Due to the dewatering properties of alcohols, many clinicians use 70\% isopropyl alcohol to dry canals before the filling. The research of $70 \%$ isopropyl alcohol, which was done by Engel et al., found that, although it has a drying effect, its use does not affect the penetration of the sealant into the dentinal tubules [58]. The authors think that $70 \%$ isopropyl alcohol, which contains 30\% water, is not sufficiently effective in drying the dentinal tubules and the sealant does not penetrate more canals than in the case when a canal is dried only with filters paper. In in vitro studies which were conducted by Suchodolski et al. [25], two rinse protocols were compared. In the first protocol of rinsing, which was ended with the use of isopropyl alcohol, a negative effect was found on the tightness of the epoxy sealant (2Seal) and the sealant-based on MTA (MTA Fillapex). In the second protocol, the use of chlorhexidine as the last rinsing agent led to the improvement of the filling tightness. Plus-NanoCare ${ }^{\circledR}$ is a formulation based on isopropyl alcohol with silver nanoparticles, used for the final root canal rinse. This formulation is a very effective antibacterial agent and it enhances the adhesion of the material to root dentin [4]. The NanoCare Plus bactericidal effect is associated with the presence of a carrier in which the nano-silver colloid is suspended. Nano-silver particles, which are bactericidal and bacteriostatic, remain a long time following treatment after the carrier on the walls of the root canals have evaporated.

\section{References}

[1] Paque F., Ganahl D., Peters O.A.: Effects of root canal preparation on apical geometry assessed by micro-computed tomography. J. Endod. 2009, 35, 1056-1059.

[2] Peters O.A., Laib A., Gohring T.N., Barbakow F.: Changes in root canal geometry after preparation assessed by high-resolution computed tomography. J. Endod. 2001, 27, 1-6.

[3] Sjogren U., Figdor D., Persson S., Sundqvist G.: Influence of infection at the time of root filling on the outcome of endodontic treatment of teeth with apical periodontitis. Int. Endod. J. 1997, 30, 297-306.

[4] Arabska-Przedpe£ska B., Pawlicka H.: Present endodontics in practice. Bestom DENT Onet.pl, Łódź 2011 [in Polish].

[5] Zehnder M.: Root canal irrigants. J. Endod. 2006, 32, 389-393.

[6] Hancock H.H. 3Rd, Sigurdsson A., Trope M., Moiseiwitsch J.: Bacteria isolated after unsuccessful endodontic treatment in North American population. Oral Surg. Oral Med. Oral Pathol. Oral Radiol. Endod. 2001, 91, 579-586.

[7] Ruff M.L., McClanahan S.B., Babel B.S.: In vitro antifungal efficiency of four irritants as a final rinse. J. Endod. 2006, 32, 331-333.

[8] Wujec P., Pawlicka H.: Irrigants recommended in root canal treatment-literature review. Dent. Med. Probl. 2008, 45, 466-472 [in Polish].

[9] Wilczyńska K., Kwiatkowska M., Wilczyński M.: Root canal system irrigation - literature review. Stomatol. Współcz. 2014, 21, 2, 34-40 [in Polish].

[10] LIPSKI M.: Sodium hypochlorite in tooth endodontic treatment. Magazyn Stomatol. 1994, 4, 1, 14-16 [in Polish].

[11] Barańska-Gachowska M.: Endodontics of development and mature age. Wyd. Czelej, Lublin 2011 [in Polish].

[12] Stojicic S., Shen Y., Qian W., Johnson B., Haapasalo M.: Antibacterial and smear layer removal ability of a novel irrigant, QMIX. Int. Endod. J. 2012, 45, 363-371.

[13] Gomes B.P.F.A., Ferraz C.C.R., Vianna M.E., Berber V.B., Teixeira F.B., Souza-Filho F.: In vitro antimicrobial activity of several concentrations of sodium hypochlorite and chlorhexidine gluconate in the elimination of Enterococcus faecalis. Int. Endod. J. 2001, 34, 424-428.

[14] Lipski M., WoźNiAK K., Lichota D., GóRski M., ŁAGocka R.: Usefulness of File-Eze preparate during ultrasonic preparation of root canal-scanning electron microscope investigation. Magazyn Stomatol. 2002, 12, 5, 24-26 [in Polish].

[15] Sirtes G., Waltimo T., Schaetzie M., Zehnder M.: The effects of temperature on sodium hypochlorite shortterm stability, pulp dissolution capacity, and antimicrobial efficiency. J. Endod. 2005, 31, 669-671.

[16] Malicka B., Ziętek M., Grzebieluch W.: Use of chlorhexidine in dentistry. Dent. Med. Probl. 2005, 42, 497-505 [in Polish].

[17] Venghat S., Hegde M., Shetty C.: Irrigants used in endodontics. Int. J. Curr. Microbiol. App. Sci. 2014, 3, $126-132$.

[18] Okino L.A., Sigueira E.L., Santos M., Bombana A.C., Figueiredo J.A.: Dissolution of pulp tissue by aqueous solution of chlorhexidine digluconate and chlorhexidine digluconate gel. Int. Endod. J. 2004, 37, 38-41.

[19] Onca O., Hosgor M., Hilmioglu S., Zekioglu O., Eronat C., Burhanoglu D.: Comparison of antibacterial and toxic effects of various root canal irrigants. Int. Endod. J. 2003, 36, 423-432.

[20] SHAfer E.: Irrigation of the root canal. Endodontie, 2007, 1, 11-27.

[21] Basrani B.R., Manek S., Sodhi R.N., Fillery E., Manzur A.: Interaction between sodium hypochlorite and chlorhexidine gluconate. J. Endod. 2007, 33, 966-969. 
[22] Basrani B.R., Manek S., Fillery E.: Using diazotization to characterize the effect of heat or sodium hypochlorite on 2\% chlorhexidine. J. Endod. 2009, 36, 312-314.

[23] Basrani B.R., Manek S., Mathers D.I., Fillery E., Sodhi R.N.: Determination of 4-chloroaniline and its derivatives formed in the interaction of sodium hypochlorite and chlorhexidine by using gas chromatography. J. Endod. 2010, 36, 312-314.

[24] Mortenson D., Sadilek M., Flake N.M., Pararype A., Heling I., Johnson J.D., Cohence N.: The effect of using an alternative irrigant between sodium hypochlorite and chlorhexidine to prevent the formation of para-chloroaniline within the root canal system. Int. Endod. J. 2012, 45, 878-882.

[25] Suchodolski Ł., Wilkoński W., Jamróz-Wilkońska L., Gabryś S., Krupiński J., OpiŁa J.: Influence of rinsing root canal protocols for sealness of gutta-percha fillings with two root canal sealers MTA-Fillapex and 2Seal. Magazyn Stomatol., 2011, 21, 7-8 [online in Polish].

[26] Riuz-Linares M., Ferrer-Luque C., Arias-Moliz T., Castro P. Aguado B., Baca P.: Antimicrobial activity of alexidine, chlorhexidine and cetrimide against Streptococcus mutans biofilm. Ann. Clin.Microbiol. Antimicrob. $2014,13,41-28$

[27] Silveira L., Baca P., Arias-Moliz M., Rodriguez-Archilla A., Ferrer-Luque C.: Antimicrobial activity of alexidine alone and associated with $\mathrm{N}$-acetylcysteine against Enterococcus faecalis biofilm. Int. J. Oral Sci. $2013,5$. $146-149$.

[28] Rita Cн., Nikhil V.: Emerging trends in Endodontic Irrigants: WHO will write the last line? Endodontol. 2014, 26 Issue 2.

[29] Mujoo T., Ballal V.: Novel root canal irrigants: an endodontic experience. Int. J. Dent. Health Sci. 2014, 1, 356-366.

[30] Kim H.S., Zhu Q., Baek S.H., Jung I.Y., Son W.J., Chang S.W., Lee W., Gu Y., Lee Y., Hong S.T., Bae K.S., Kiм J.W., Сно K., Kum K.Y.: Chemical interaction of alexidine and sodium hypochlorite. J. Endod. 2012 38, $112-116$.

[31] Tirali R.E., Turan Y., Akal N., Kaharanz Z.C.: In vitro antimicrobial activity of several concentrations of $\mathrm{NaOCl}$ and Octenisept in elimination of endodontic pathogens. Oral Surg. Oral Med. Oral Pathol. Oral Radiol. Endod. 2009, 108, e117-e120.

[32] Tandjung L., Waltimo T., Hauser I., Heide P., Decher E.M., Weiger R.: Octenidine in root canal dentin disinfection ex vivo. Int. Endod. J. 2007, 40, 845-851.

[33] Makkar S., Aggarwal A., Parischa S., Kapur I.: Comparative evaluation of octenidine hydrochloride as antibacterial root canal irrigant. Indian J. Oral Sci. 2015, 6, 10-13.

[34] De Lucena J.M.V.M., Decker E.M., Walter C., Boeira L.S., Lost C., Weiger R.: Antimicrobial effectiveness of intracanal medicaments on Enterococcus faecalis: chlorhexidine versus octenidine. Int. Endod. J. 2013, 46, 53-61.

[35] Tirali R.E., Gulsahi K., Cehreli S.B., Karahan Z.C., Uzunoglu E., Elhan A.: Antimicrobial efficacy of octenidine hydrochloride, MTAD and chlorhexidine gluconate mixed with calcium hydroxide. J. Contemp. Dent. Pract. 2013, 14, 456-460.

[36] Tirali R.E., Bodur H., Sipahi B., Sungurtekin E.: Evaluation of the antimicrobial activities of chlorhexidine gluconate, sodium hypochlorite and octenidine hydrochloride in vitro. Aust. Endod. J. 2013, 39, 15-18.

[37] Anuradha B., Indira R., Lalitha M.K., Sriram T.: A new irrigant against E. faecalis in root canal disinfection. Biosci. Biotechnol. Res. Asia, 2014, 11, 121-127.

[38] Eldeniz A.U., Guneser M.B., Aквulut M.B.: Comparative antifungal efficacy of light activated disinfection and octenidine hydrochloride with contemporary endodontic irrigants. Lasers Med. Sci. 2015, 30, 669-675.

[39] Kustra P., Zarzecka J.: Chemical preparation of endodontic system - literature review. Twój Przeg. Stomatol. 2009, 9, 44-51 [in Polish].

[40] Lipski M., Lichota D., Górski M., Dura W., DroźDzik A.: Root canal walls purity with unfinished development of root, irrigated 2\% chlorhexidine. SEM examination. Annual PAM, 2013, 59, 81-85 [in Polish].

[41] Violich D.R., Chandler N.P.: The smear layer in endodontics - a review. Int. Endod. J. 2010, 43, 2-15.

[42] Wujec P., PAwlicka H.: Interactions between irrigants used in endodontic treatment. Magazyn Stomatol. 2011, 21, 2, 64-67 [in Polish].

[43] Stachera N., Kroczyńska P., Gaj E., Lipski M.: Smear layer influence for root canal filling sealness made with Gutta Flow sealant. In vitro examinations. Magazyn Stomatol. 2011, 21, 9, 131-134 [in Polish].

[44] Czonstкowsky M., Wilson E.G., Holstein F.A.: The smear layer in endodontics. Dent. Clin. North Am. 1990, $34,13-25$.

[45] Sen B.H., Wesselink P.R., Tarkan M.: The smear layer a phenomenon in root canal therapy. Int. Endod. J. 1995, $28,141-148$.

[46] Castellucci A., West D.: Endodontics. Florence, Il Tridente 2005.

[47] Kuah H.G., Lui J.N., Tseng P.S., Chen N.N.: The effect of EDTA with and without ultrasonics on removal on the smear layer. J. Endod. 2010, 36, 512-514.

[48] Grawehr M.: Interactions of ethylenediamine tetraacetic acid with sodium hypochlorite an aqueous solutions. Int. Endod. J. 2003, 36, 411-415.

[49] Wong S., Mundy L., Chandler N., Upritchard J., Purton D., Tompkins G.: Antibacterial properties of root canal lubricants: A comparison with commonly used irrigants. Aust. Endod. J. 2014, 40, 111-115

[50] Lipski M.: Lubricants used during endodontic treatment. Magazyn Stomatol. 2002, 12, 9, 106-107 [in Polish].

[51] Prado M., Gusman H., Gomes B.P.F.A., Simao R.A.: Scanning electron microscopic investigation of the effectiveness of phosphoric acid in smear layer removal when compared with EDTA and citric acid. J. Endod. 2011, 37, $255-258$. 
[52] Pawlicka H.: Citric acid effectiveness evaluation as root canal irrigant. SEM examinations. Stomatol. Współcz. 1995, 2, 539-543 [in Polish].

[53] Portenier I., Waltiomo T., Orstavik D., Haapasalo M.: Killing of Enterococcus faecalis by MTAD and chlorhexidine digluconate with or without cetrimide in the presence or absence of dentine powder or BSA. J. Endod. 2006, 32, 138-141.

[54] Pawlicka H., Pietrzak P.: Enterococcus faecalis - its role in endodontic treatment and methods of elimination from infected root canals. Dent. Med. Probl. 2007, 44, 390-395 [in Polish].

[55] Suchodolski Ł., Łaszkiewicz J., Ciesielski P.: Methods of Enterococcus faecalis elimination from infected root canals - literature review. Czas. Stomatol. 2007, 60, 111-117 [in Polish].

[56] Stevens R.W., Strother J.M., McClanahan S.B.: Leakage and sealer penetration in smear-free dentin after final rinse with 95\% ethanol. J. Endod. 2006, 32, 785-788.

[58] Wilcox L.R., Wiemann A.H.: Effect of final alcohol rinse on sealer coverage of obturated root canals. J. Endod. 1995, 21, 256-258.

[59] Engel G.T., Goodel G.G., McClanahan S.B.: Sealer penetration and apical microleakage in smear-free dentin after final rinse with either 70\% isopropyl alcohol or peridex. J. Endod. 2005, 31, 620-623.

\section{Address for correspondence:}

Marta Mrużyńska

Racławicka 29/1H

53-149 Wrocław

Poland

E-mail: marta.mruzynska@interia.pl

Conflict of Interest: None declared

Received: 29.05 .2015

Revised: 17.07.2015

Accepted: 18.08.2015 